\title{
PAPR Reduction in OFDM Systems using RCF and SLM Techniques
}

\author{
Manjula A. V. \\ Asst. Professor \\ Department of E\&C \\ NIEIT, Mysore, India
}

\author{
K. N. Muralidhara, PhD \\ Professor \\ Department of E\&C, \\ P.E.S College of Engineering, \\ Mandya,India
}

\begin{abstract}
Orthogonal Frequency Division Multiplexing is considered as one of the prominent technology for $4 \mathrm{G}$ communication to achieve high data rate, spectral efficiency over multipath fading channel. However one of the major drawbacks of OFDM system is high PAPR. Repetitive clipping and filtering $(\mathrm{RCF})$ and selective mapping (SLM) techniques being considered as simple and less complex compare to other techniques, both techniques are analysed and simulated result will give significant reduction in PAP ratio.
\end{abstract}

\section{Keywords}

Orthgonal Frequency Division Multiplexing(OFDM), Peakto-Average Power Ratio(PAPR), Complimentary Cumulative Distribution Function(CCDF), Selective mapping(SLM), Repetitive clipping and filtering(RCF)

\section{INTRODUCTION}

OFDM is special type of the multicarrier modulation technique divides the entire frequency selective fading channel into many orthogonal narrow band flat fading channel in which high bit rate data stream is transmitted in parallel over number of low bit rate subcarriers there by substantially reducing the inter symbol interference [1] and improved spectral efficiency. Advancement in digital signal processing and VLSI technology, OFDM can be easily implemented using FFT/IFFT.

OFDMA/OFDM is used in IEEE $802.11 \mathrm{a} / \mathrm{g} / \mathrm{n}$ WLAN, HIPERLAN/2, WiMAX, DVBT,Asymmetric Digital Subscriber Line (ADSL), very high rate DSL (VDSL), and others. It has also been chosen as the physical layer architecture for 3GPP long-term evolution (LTE)[2].

However OFDM systems suffers from high PAPR, requires tight synchronization between transmitter and receiver other

wise leads to carrier frequency offset errors. High peak values in OFDM system results from superposition of large number of statistically independent sub channels that can constructively sum up high peaks[2] .It is shown that as number of carriers increases, PAPR also increases. The PAP ratio is approximately equal to $\mathrm{N}$, where $\mathrm{N}$ is the number of sub carriers. High PAP ratio results in amplifier to work in large dynamic range which decreases the efficiency of power amplifier, DAC and ADC.

PAP ratios analyzed using $\mathrm{CCDF}$ ( Complimentary cumulative distributive function)plots. Various PAPR reduction techniques are Clipping \& filtering[4-8], , selective mapping [8-13],Partial transmit sequence[12-15], nonlinear companding,Tone Injection, Tone Reservation[16], Active Constellation[17] and coding techniques[25-26]. Although many techniques found in the literature to reduce PAPR ratio in OFDM systems . RCF and SLM is most widely used and less complex. Here RCF and SLM techniques are studied and simulated results gives significant decrease in PAP ratio.

\section{BASICS OF OFDM, PAPR AND CCDF 2.1 OFDM}

Consider an OFDM system consisting of $\mathrm{N}$ subcarriers. Let a block of $\mathrm{N}$ symbols $\mathrm{X}=\{\mathrm{Xk}, \mathrm{k}=0,1,---\mathrm{N}-1\}$ is a data block, each symbol modulating on one set of subcarriers. The complex base band representation of multicarrier signal consisting of $\mathrm{N}$ subcarriers is given by

$x(t)=\frac{1}{\sqrt{N}} \sum_{k=0}^{N-1} X_{k} e^{j 2 \pi f_{k}} t, \quad 0 \leq t \leq$

NT (1) (1)

Where $X_{k}$ is transmitted symbol on $\mathrm{k}^{\text {th }}$ subcarrier and $\mathrm{j}=\sqrt{-1}, \Delta f$ is the sub carrier spacing and NT denotes useful data block period.

\subsection{PAPR}

In general the PAPR of OFDM signal is defined as the ratio of the maximum instantaneous power to its average power.

$\operatorname{PAPR}[x(t)]=\frac{\max _{0 \leq t \leq N T}\left[|x[t]|^{2}\right]}{P_{a v}}$

To better approximate the PAPR of continuous signals, the OFDM signals are L times oversampled. From the literature

It is studied that L is approximately equal to 4 is sufficient to get accurate PAPR results. Therefore the L-times oversampled time domain OFDM signal samples can be defined as

$x[n] \triangleq \frac{1}{\sqrt{N}} \sum_{k=0}^{N-1} X_{k} e^{\frac{j 2 \pi n k}{L N}}, 0 \leq n \leq L N-1$

(3)

Where $\mathrm{E}\{$.$\} denotes the expectation operator$

\subsection{Complimentary Cumulative \\ Distribution Function(CCDF)}

It is a statistical technique as shown in Fig. 1 that provides the amount of time ,a signal spends above given power level. In modern communication CCDF measurement is considered as one of the precious tool offers comprehensive analysis of signal power peaks. For sufficient large number of sub carriers ,the amplitude of multicarrier signal, CCDF expression for OFDM signal can be written as

$$
\begin{gathered}
P(P A P R>z)=1-P(P A P R \leq z) \\
=1-F(z)^{N} \\
=1-(1-\exp (-z))^{N}
\end{gathered}
$$


Where $\mathrm{N}$ signal samples are statistically independent uncorrelated.

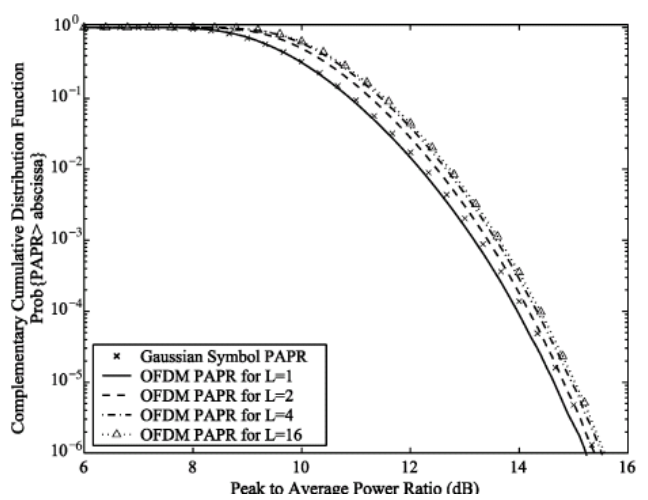

Fig 1. Distribution of PAPR of OFDM signal samples oversampled by different $L$.

\section{REPETITIVE CLIPPING AND FILTERING}

This is signal distortion based technique as shown in Fig.2.In this method the L times oversampled discrete time signal $x^{I}[m]$ is generated from the IFFT equation 3i.e.

$X^{I}[K]$ with $\mathrm{N}(\mathrm{L}-1)$ zero padding in frequency domain) is then modulated its carrier frequency $f_{c}$ to get passband signal and clipped version of the signal is given by

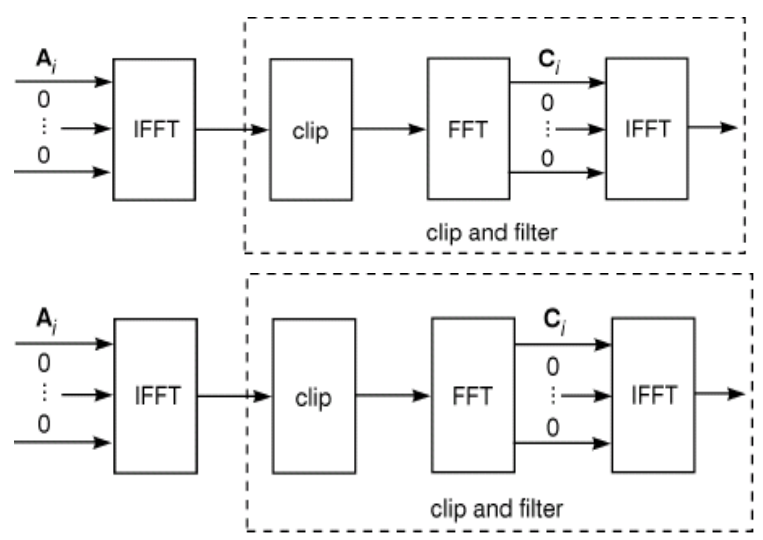

Fig.2 Block diagram of Clipping and Filtering

$$
x_{c[m]}^{p}=\left\{\begin{array}{ll}
-A & x^{p}[m] \leq-A \\
A & \left|x^{p}[m]\right| \\
x^{p}[m] \geq A
\end{array}\left|x^{p}[m]\right|<\right.
$$

$A$

clipping ratio is defined as $\mathrm{CR}=\mathrm{A} / \sigma$. Where $\mathrm{A}$ is specified clipping level and $\sigma$ is RMS value of OFDM signal

Filtering can reduce out of band radiation and clipping of the signal amplitude causes peak re growth . Jean Armstrng et.al[4] proposed repetitive clipping and filtering for further reduction in PAP ratio. But number of iterations are more than clip and filter methods. clip and filter and repetitive clip and filtering methods are used to reduce PAP ratio. simulated for different clipping ratios.

\section{SELECTIVE MAPPING}

In SLM technique as shown in Fig. 3 the data block $X=$ $[X[0], X[1], \ldots \ldots \ldots, X[N-1]]$ is multiplied with different phase sequences generate alternate input data sequences $\quad B^{v}=\left[\begin{array}{llll}B_{0}^{v}, & B_{1}^{v} & \ldots \ldots & B_{[N-1]}^{v}\end{array}\right]^{T}$ to $X^{(0)}, X^{(1)}, \ldots \ldots \ldots \ldots X^{(V-1)}$, the time domain sequences for these data sequences obtained by applying IFFT. Among these time domain sequences $x^{(0)}, x^{(1)}, \ldots \ldots \ldots \ldots x^{(V-1)}$ the one with lowest PAPR is selected for transmission. In this method the phase sequences must be known to both transmitter and receiver. In the literature different methods which does not require side information are proposed[14]

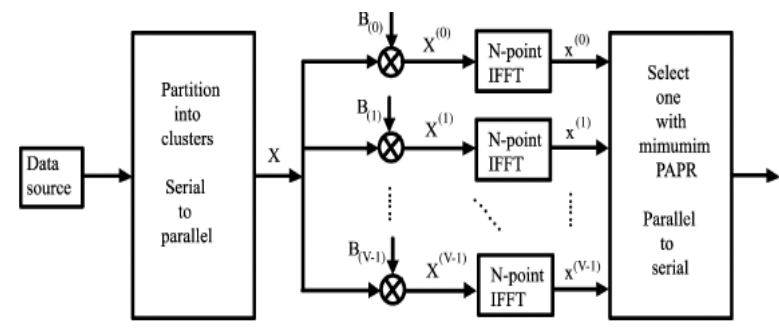

Fig.3 Block diagram of SLM technique

\section{SIMULATION RESULTS OF RCFAND SLM}

Clipping and filtering applied to OFDM system and simulated using MATLAB. Results Obtained for single clip and filtering with different clipping ratios $\mathrm{CR}=0.4,1,2$ and 4 with reference to obtained result as clipping ratio decreases BER decreases. Futher results obtained for iterative clipping and filtering method, with this method PAPR reduces for more iterations(with increased computational complexity).

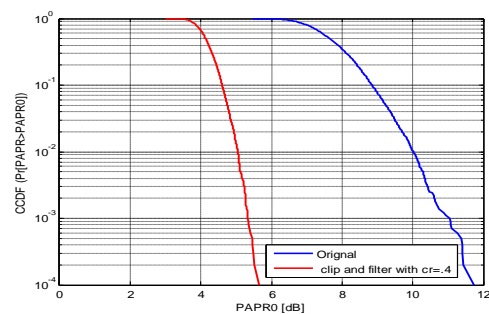

Fig.4 PAPR performance of clipping and filtering with $\mathrm{CR}=.4$

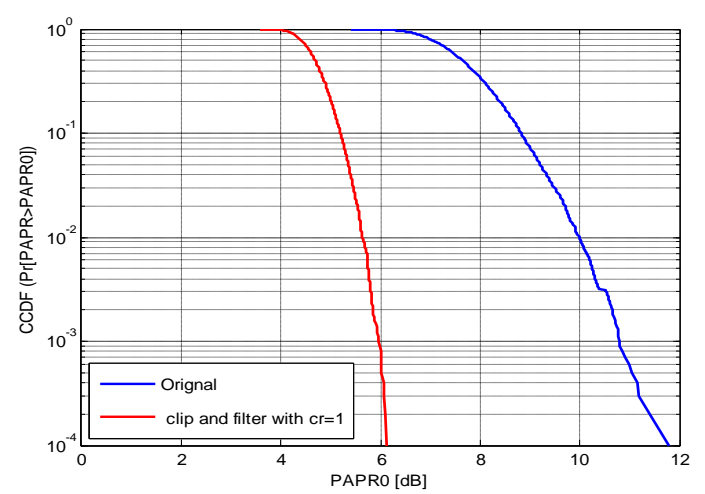

Fig.5 PAPR performance of clipping and filtering with $\mathrm{CR}=1$ 


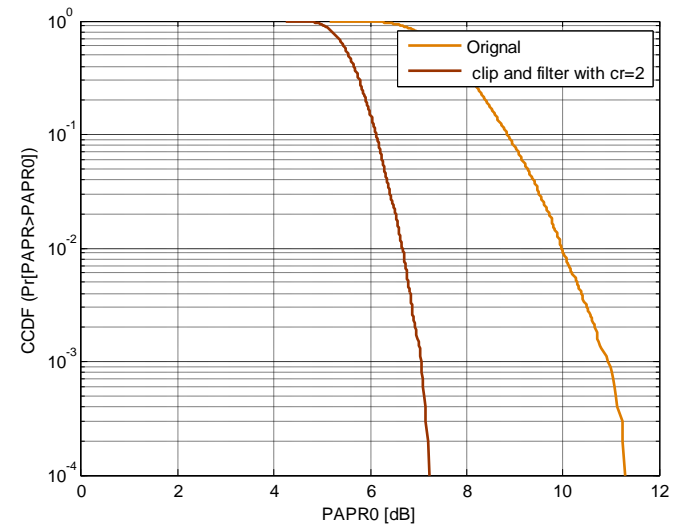

Fig.6 PAPR performance of clipping and filtering with $\mathbf{C R}=2$

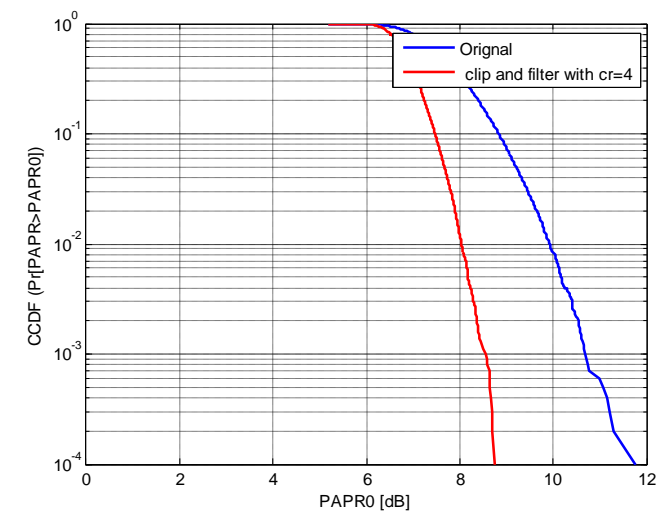

Fig.7 PAPR performance of clipping and filtering with $\mathrm{CR}=4$

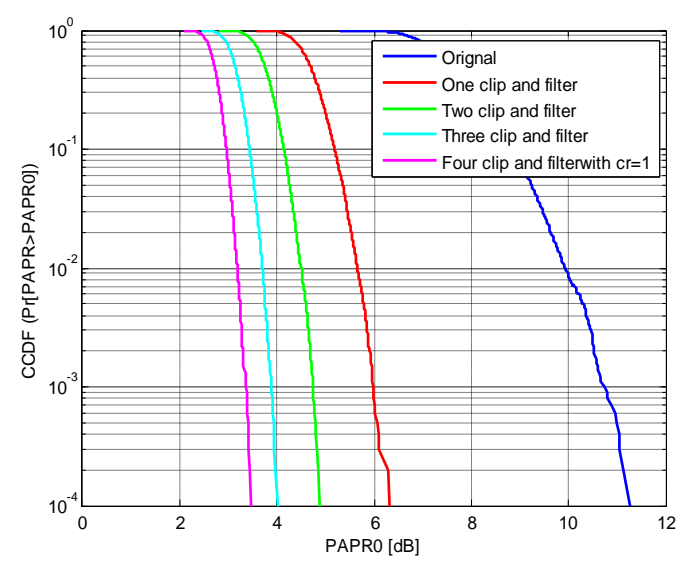

Fig.8 PAPR performance of repetitive clipping and filtering with $\mathrm{CR}=1$

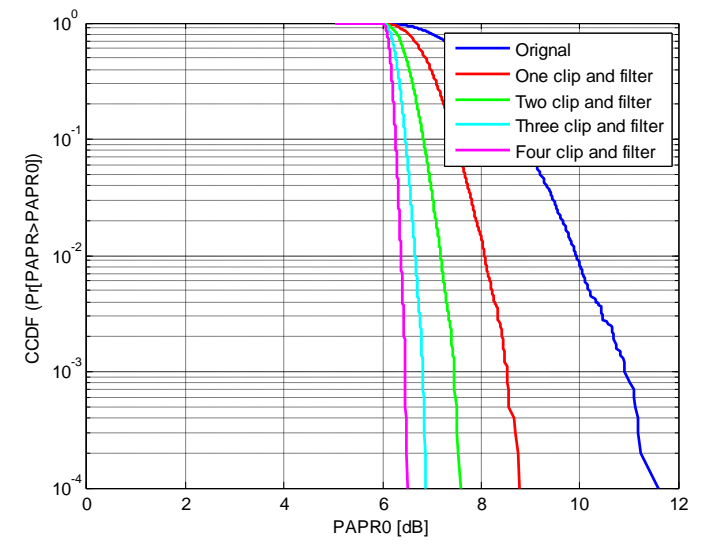

Fig.9 PAPR performance of repetitive clipping and filtering with $C R=4$

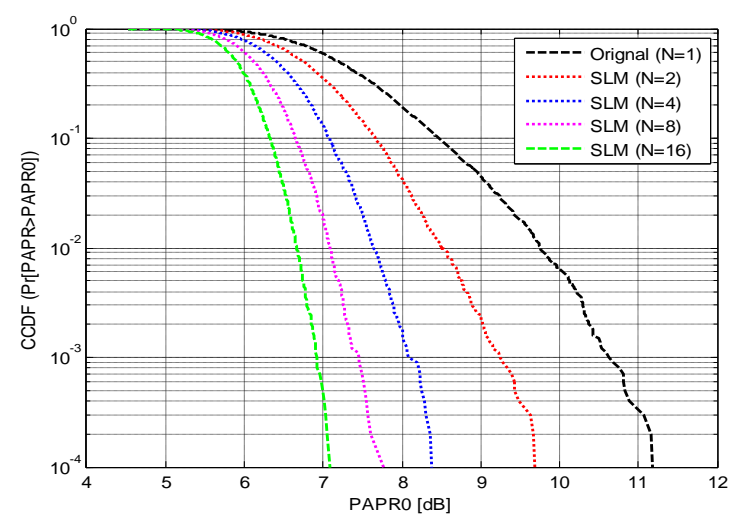

Fig.10 PAPR performance of selective mapping technique with different phase sequences

\section{CONCLUSION}

OFDM is a Multicarrier transmission technique is a very attractive technique for high-speed transmission over a faded communication channel. The PAPR problem is one of the important issues to be addressed in developing multicarrier transmission systems, two simple PAPR reduction techniques are used to reduce the peak $t$ average power ratio to significant level. Simulated results are summarized in the Table 1 as shown.Further combining both the methods as hybrid technique to reduce PAPR ratio.

Table 1. PAPR Performance of RCF and SLM Techniques

\begin{tabular}{|c|c|c|c|}
\hline $\begin{array}{l}\text { No.of OFDM } \\
\text { symbols }\end{array}$ & 100000 & $\begin{array}{l}\text { PAPR } \\
\text { (original) }\end{array}$ & $11.253 \mathrm{db}$ \\
\hline $\begin{array}{l}\text { Mdulation } \\
\text { technique }\end{array}$ & $\begin{array}{l}\text { QPSK } \\
\text { Modulation }\end{array}$ & $\begin{array}{l}\text { PAPR(clf } \\
\text { with } \mathrm{cr}=1)\end{array}$ & $7.27 \mathrm{~dB}$ \\
\hline Clipping Ratio & $0.4,1,2,4$ & $\begin{array}{l}\text { PAPR (RCLF } \\
\text { with } \mathrm{cr}=1) 4 \\
\text { iteration }\end{array}$ & $2.06 \mathrm{db}$ \\
\hline No. of ffts & 128 & \multirow{3}{*}{$\begin{array}{l}\text { SLM } \\
\text { technique } \\
\mathrm{K}=128 \text { (no. of } \\
\text { ffts) }\end{array}$} & \multirow{3}{*}{$\begin{array}{l}\mathrm{N}=2, \\
\mathrm{PAPR}=9.76 \\
\mathrm{~dB} \\
\mathrm{~N}=16 \\
\mathrm{PAPR}=7.09 \\
\mathrm{~dB}\end{array}$} \\
\hline $\begin{array}{l}\text { Oversampling } \\
\text { factor }\end{array}$ & 2 & & \\
\hline $\begin{array}{l}\text { No of } \\
\text { iterations }\end{array}$ & 1,4 & & \\
\hline
\end{tabular}




\section{REFERENCES}

[1] Jiang T., Wu Y., "An Overview: Peak-to-average power ratio reduction techniques for OFDM signals", IEEE Transactions on Broadcasting, vol. 54, no. 2, pp. 257268, Jun 2008.

[2] S. H. Han and J. H. Lee, "An overview of peak-toaverage power ratio reduction techniques for multicarrier transmission," IEEE Wireless Commun., vol. 12, no. 2, pp. 56-65, Apr. 2005.

[3] Nee, R. V. and R. Prasad, OFDM for Wireless Multimedia Communications, ArtechHouse Publishers, Norwood, MA,January 2000.

[4] J. Armstrong, "Peak-to-average reduction for OFDM by repeated clip-ping and frequency domain filtering," IEEE Electron. Lett., vol. 38, pp. 246-247, May 2002

[5] Xiaodong Li and Cimini, L.J. Jr., "Effects of clipping and filtering on the performance ofOFDM," IEEE Communications Letters, pp.131- 133, May 1998

[6] L. Wang, C. Tellambura, "A simplified Clipping and Filtering Technique for PAR Reduction in OFDM Systems,"IEEE Signal Processing Lett., vol.12,no. 6, pp.453-456, Jun. 2005

[7] Z. Kollár, L. Varga, and K. Czimer, "Clipping-based iterative PAPRreduction techniques for FBMC," in Proceedings of the OFDM-Workshop (InOWo '12), pp. 139-145, August 2012.

[8] Sharma, P.K., Seema Verma and Basu, A.O. "Modified clipping and filtering technique for peak-to-average power ratio reduction of OFDM signals used in WLAN", International Journal of Engineering Science and Technology, Vol. 2(10), 2010

[9] R. Bauml, R. Fischer, and J. Huber, "Reducing the peakto-average power ratio of multicarrier modulation by selected mapping," Electronic Letters, vol. 32, pp. 20562057, 1996

[10] S. H. Han and J. H. Lee, "Modified selected mapping technique for PAPR reduction of coded OFDM signal," IEEE Trans. Broadcast., vol. 50, no. 3, pp. 335-341, Sept. 2004

[11] S. J. Heo, H. S. Noh, J. S. No, and D. J. Shin, "A modified SLM scheme with low complexity for PAPR reduction of OFDM systems," IEEE Trans. Broadcasting, vol. 53, no. 4, pp. 804-808, Dec. 2007.

[12] Alavi, C. Tellambura, and I. Fair, "PAPR reduction of OFDM signals using partial transmit sequence: An optimal approach using sphere decoding," IEEE Trans.
Communications Letters, vol. 9, no. 11, pp. 982-984, Nov. 2005

A. D. S. Jayalath and C. Tellambura, "SLM and PTS peakreduction of OFDM signals without side information," IEEE Trans.Wireless Commun., vol. 4, no. 5, pp. 20062013, Sept. 2005.

[13] Muller S. H., Huber J. B., "OFDM with reduced peak-toaverage power ratio by optimum combination of partial transmit sequences", Electronics Letters, vol. 33, no. 5,pp. 36-69, Feb. 1997

[14] L. J. Cimini, Jr. and N. R. Sollenberger, "Peak-to-verage Power Ratio Reduction of an OFDM Signal Using Partial Transmit Sequences," IEEE Commun. Lett., vol. 4, no. 5, pp. 86-88, Mar. 2000

[15] B. Krongold and D. Jones, "An active-set approach for ofdm par reduction via tone reservation," IEEE Trans. Signal Processing, vol. 52, pp. 495-509, Feb. 2004.

[16] B. Krongold and D. Jones, "Par reduction in ofdm via active constellation extension," IEEE Trans. Broadcasting, vol. 49, pp. 258-268, Sept.2003.

[17] T. Jiang and G. X. Zhu, "Complement block coding for reduction in peak-to-average power ratio of DMsignals," IEEE Communications

Magazine, vol. 43, no. 9, pp. S17-S22, Sept. 2005.

[18] K.Yang and S. Chang, "Peak-to-average power control inOFDM using standard arrays of linear block codes," IEEE Communications Letters,

vol. 7, no. 4, pp. 174-176, Apr. 2003

[19] J. Armstrong, Peak-to-average power reduction for OFDM by repeated clipping and frequency domain filtering, IEE Electronics Letters, vol. 38, pp. 246-247, February 2002.

[20] Jiang T., Xiang W., Richardson P. C., Qu D., Zhu G., "On the Nonlinear Companding Transform for Reduction in PAPR of MCM Signals", IEEE Transactions on Wireless Communications, vol. 6, no. 6, pp.2017-2021, June 2007.

[21] Jiang T., Yang Y., Song Y., "Exponential companding transform for PAPR reduction in OFDM systems", IEEE Transactions on Broadcasting, vol. 51, no. 2, pp. 244 248, June 2005

[22] C.L.Wang and Y. Ouyang, "Low-complexity selected mapping schemes for peak-toaverage power ratio reduction in OFDM system", IEEE Transactions on Signal Processing,vol. 53, Dec 2005. 